\title{
Avaliação de danos causados pelo Tomato severe rugose virus (ToSRV) em cultivares de pimentão
}

\author{
Kelly Cristina Rocha ${ }^{1}$; Renate Krause Sakate ${ }^{1}$; Marcelo Agenor Pavan ${ }^{1}$; Rômulo Fugito Kobori²; Ricardo Gioria ${ }^{2}$; \\ Valdir Atsushi Yuki ${ }^{3}$
}

${ }^{1}$ Departamento de Produção Vegetal, Setor Defesa Fitossanitária, UNESP, Faculdade de Ciências Agronômicas, CEP 18603-970, Botucatu, SP; ${ }^{2}$ Sakata Seed Sudamérica, Bragança Paulista, SP.; ${ }^{3}$ Instituto Agronômico (IAC), Cx. Postal 28, CEP 13012-970, Campinas, SP.

Autor para correspondência: Renate Krause Sakate (renatekrause@fca.unesp.br)

Data de chegada: 28/06/2011. Aceito para publicação em: 08/02/2012.

\section{RESUMO}

Rocha, K.C.; Krause-Sakate, R.; Pavan, M.A.; Kobori, R.F.; Gioria, R.; Yuki, V.A. Avaliação de danos causados pelo Tomato severe rugose virus (ToSRV) em cultivares de pimentão. Summa Phytopathologica, v.38, n.1, p.87-89, 2012.

\begin{abstract}
A espécie Tomato severe rugose virus (ToSRV) é a predominante em áreas de cultivo de pimentão no Estado de São Paulo. Sua ocorrência na cultura é relativamente recente de modo que não existem informações sobre os danos causados nesta cultura. Os objetivos do presente trabalho foram avaliar a produtividade e qualidade dos frutos de pimentão de três cultivares (Magda, Amanda e Rubia R) quando
\end{abstract}

infectadas com o ToSRV. Verificou-se acentuada redução no número de frutos e menor crescimento das plantas, porém, o ToSRV não influenciou significativamente na massa, diâmetro e comprimento dos frutos. Os resultados obtidos até o momento permitem concluir que o ToSRV causa danos em pimentão e que há necessidade de estudos visando resistência ao ToSRV.

Palavras-chave adicionais: Bemisia tabaci, Begomovirus, Capsicum

\section{ABSTRACT}

Rocha, K.C.; Krause-Sakate, R.; Pavan, M.A.; Kobori, R.F.; Gioria, R.; Yuki, V.A. Yield losses caused by Tomato severe rugose virus (ToSRV) in pepper cultivars. Summa Phytopathologica, v.38, n.1, p.87-89, 2012.

Tomato severe rugose virus (ToSRV) is the predominant species of begomovirus affecting pepper crops in São Paulo State, Brazil. Its occurrence is relatively recent for the culture thus, there is no information on yield losses caused by this virus on sweet pepper. The aims of this study were to evaluate yield and fruit quality of three pepper cultivars (Magda, Amanda and Rubia R) infected with ToSRV. There was marked reduction in the number of fruits and in the growth of plants; however, ToSRV did not significantly influence the average weight, diameter and the length of fruits. The results obtained so far lead to the conclusion that ToSRV causes damage in peppers and it is necessary the development of resistant cultivars to ToSRV.

Keywords: Bemisia tabaci, Begomovirus, Capsicum

Diferentes espécies de vírus infectam o gênero Capsicum no Brasil, incluindo as do gênero begomovírus $(2,4,6)$. O gênero Begomovirus é o mais importante dentro da família Geminiviridae, seu genoma é constituído por DNA circular (ssDNA), encapsidado em partículas icosaédricas geminadas (7) e no Brasil prevalecem os begomovírus bipartidos, com presença dos componentes A e B. A transmissão e dispersão de begomovírus no campo ocorre pelas moscas-brancas, espécie Bemisia tabaci, classificadas na ordem Hemiptera (Família: Aleyrodidae) (7).

As espécies de begomovírus hoje relatadas em pimenta e pimentão no país, o ToRSV e o Tomato yellow vein streak virus- ToYVSV (4, 6), são as mesmas que vem acarretando danos significativos na cultura do tomateiro. Desde a primeira constatação de begomovírus em plantas do gênero Capsicum, levantamentos realizados recentemente no estado de São Paulo indicam que a incidência em pimentão está cada vez mais frequente e que o ToSRV predomina no Estado de São Paulo tanto em pimentão quanto em tomateiro (6). Para o tomateiro já existem dados demonstrando os danos diretos e indiretos causados pelo ToYVSV causa nesta planta $(8,3)$, porém para o pimentão nada foi demonstrado até o momento.

Deste modo o objetivo do trabalho foi avaliar o efeito da infecção pelo ToSRV na produtividade das cultivares comerciais de pimentão Amanda, Magda e Rubia R. Foi selecionado o isolado ToSRV-Sk (cedido pela Empresa Sakata Seed Sudamerica) em função de sua maior agressividade tanto em tomateiro como em pimentão.

Para a transmissão do isolado ToSRV-Sk os insetos foram mantidos em plantas de tomateiro infectadas em uma sala climatizada $\left(28^{\circ} \mathrm{C}\right.$ e $80 \%$ UR). Nesta sala, bandejas contendo as mudas com idade de 30 dias foram dispostas, quando a população de vetores era em média de 50 insetos por planta sadia, por um período de acesso de inoculação (PAI) do vírus de sete dias. A cultivar de tomateiro Santa Clara, altamente suscetível ao ToSRV foi utilizada como controle de transmissão do isolado.

Todas as mudas de pimentão inoculadas pelo ToSRV foram 
pulverizadas com inseticida e transplantadas individualmente em vasos plásticos de 5 litros, mantidas em estufa com sistema de fertirrigação por gotejamento. As plantas foram conduzidas em haste dupla, com tutoramento vertical até o sexto mês após transplantio.

As plantas foram avaliadas para a presença do vírus aos 30 e 60 dias após a inoculação. O DNA total extraído por CTAB 3\% foi submetido à reação de "Rolling Circle Amplification-RCA" seguido da reação "Polymerase Chain Reaction" (PCR) e analisados por eletroforese em gel de agarose (6).

A severidade dos sintomas nas plantas infectadas foi avaliada por meio de uma escala diagramática atribuída para plantas de pimentão (Figura 1). As avaliações dos sintomas foram realizadas periodicamente. O delineamento experimental adotado foi em blocos casualizados, com quatro repetições/cultivar, sendo cada repetição constituída de cinco plantas, tanto para plantas inoculadas e não inoculadas com o ToSRV. O experimento foi repetido duas vezes em épocas diferentes do ano ( $1^{\circ}$ experimento: meses de março a outubro e $2^{\circ}$ experimento: maio a novembro).

As plantas infectadas mostraram redução na altura final de 13,8\%, $13,1 \%$ e $18,4 \%$ para as cultivares Rubia R, Amanda e Magda, respectivamente, em relação às plantas sadias. No segundo experimento não se observou o mesmo padrão de redução significativa do crescimento das plantas para as três cultivares (Inserir Tabela 1).

Em ambos os experimentos todas as plantas inoculadas estavam infectadas pelo ToSRV quando testadas por RCA-PCR aos $30 \mathrm{DAI}$, bem como as plantas de tomateiro Santa Clara. Os sintomas foliares observados em pimentão foram de enrolamento, amarelecimento de nervuras, mosaico amarelo, mosqueado e deformação. Também notouse redução do crescimento das plantas.

A cultivar Magda foi a que recebeu maior nota de severidade de sintomas, com médias de 3,2 e 2,3 no primeiro e no segundo experimento, respectivamente (Tabela 1). Observou-se também nos três cultivares menor severidade de sintomas no segundo experimento, o que pode estar relacionado à temperatura mais baixa na estufa durante
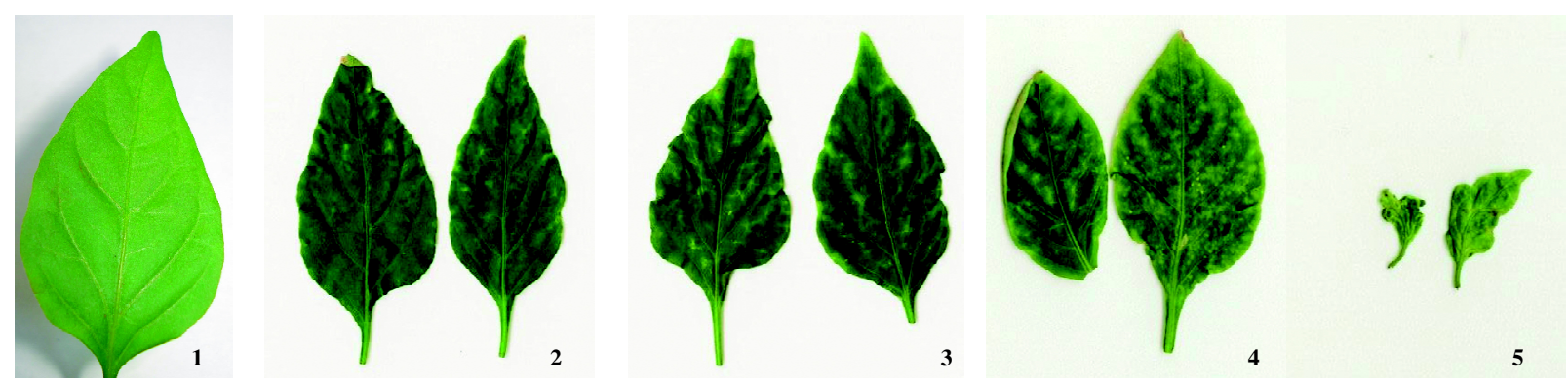

Figura 1. Escala diagramática de severidade de sintomas para plantas de pimentão inoculadas com Tomato severe rugose virus. Valor 1 = ausência de sintomas, 2 = leve mosaico internerval, 3 = clareamento de nervuras, mosaico internerval e início de enrugamento dos folíolos, $4=$ enrugamento dos folíolos e mosaico e 5 = enrugamento e deformação severa dos folíolos no terço superior da planta

Tabela 1. Altura média final, média de severidade de sintomas e produção de três cultivares de pimentão infectadas com o ToSRV e sadias, avaliada com base no número de frutos, tamanho (diâmetro e comprimento) e massa (g), em experimentos realizados em duas épocas distintas.

\begin{tabular}{|c|c|c|c|c|c|c|c|c|c|c|}
\hline \multicolumn{11}{|c|}{$1^{0}$ Experime nto } \\
\hline \multirow{2}{*}{ Variedade } & \multirow{2}{*}{ Tra tame nito } & \multirow{2}{*}{ Altura } & \multirow{2}{*}{$\begin{array}{l}\text { Nota de } \\
\text { sinto mas }\end{array}$} & \multicolumn{3}{|c|}{ Número de Frutos } & \multicolumn{2}{|c|}{ Massa $(g)$} & \multirow{2}{*}{$\begin{array}{c}\text { Dầ metro } \\
\text { cm }\end{array}$} & \multirow{2}{*}{ Co mp rimento } \\
\hline & & & & Com & Não-Co m & Total & MFC-Média & MFNC-Média & & \\
\hline \multirow{2}{*}{ RubiaR } & Infectadas & $87,4 \mathrm{~B}$ & $2,7 \mathrm{C}$ & $49 \mathrm{~B}$ & $116 \mathrm{~A}$ & $165 \mathrm{~A}$ & $170,5 \mathrm{~A}$ & $83,2 \mathrm{~A}$ & $6,6 \mathrm{~B}$ & $12,0 \mathrm{~A}$ \\
\hline & Sadias & $101,4 \mathrm{~A}$ & $1,0 \mathrm{D}$ & $68 \mathrm{~A}$ & $147 \mathrm{~A}$ & $215 \mathrm{~A}$ & $202,1 \mathrm{~A}$ & $104,5 \mathrm{~A}$ & $7,1 \mathrm{~A}$ & $12,1 \mathrm{~A}$ \\
\hline \multirow{2}{*}{ Amanda } & Infectadas & $80,7 \mathrm{~B}$ & $2,1 \mathrm{~B}$ & $62 \mathrm{~B}$ & $127 \mathrm{~A}$ & $189 \mathrm{~B}$ & $197,1 \overline{\mathrm{A}}$ & $88,1 \mathrm{~A}$ & $6,7 \mathrm{~A}$ & $14,4 \mathrm{~A}$ \\
\hline & Sadias & $92,8 \mathrm{~A}$ & $1,0 \mathrm{D}$ & $112 \mathrm{~A}$ & $173 \mathrm{~A}$ & $285 \mathrm{~A}$ & $189,4 \mathrm{~A}$ & $98,0 \mathrm{~A}$ & $6,6 \mathrm{~A}$ & $13,3 \mathrm{~A}$ \\
\hline \multirow{2}{*}{ Magda } & Infectadas & $123,1 \mathrm{~B}$ & $3,2 \mathrm{~A}$ & $93 \mathrm{~B}$ & $401 \mathrm{~A}$ & $494 \mathrm{~A}$ & $8 \overline{8}, \overline{\mathrm{A}}$ & $35,1 \mathrm{~A}$ & $5,2 \mathrm{~A}$ & $11,5 \mathrm{~A}$ \\
\hline & Sadias & $150,9 \mathrm{~A}$ & $1,0 \mathrm{D}$ & $147 \mathrm{~A}$ & $505 \mathrm{~A}$ & $652 \mathrm{~A}$ & $76,8 \mathrm{~A}$ & $29,1 \mathrm{~A}$ & $4,8 \mathrm{~B}$ & $11,0 \mathrm{~B}$ \\
\hline \multicolumn{11}{|c|}{$2^{\circ}$ Experimento } \\
\hline \multirow{2}{*}{ Variedade } & \multirow{2}{*}{ Tra tame nito } & \multirow{2}{*}{ Altura } & \multirow{2}{*}{$\begin{array}{l}\text { Nota de } \\
\text { sinto mas }\end{array}$} & \multicolumn{3}{|c|}{ Número de Frutos } & \multicolumn{2}{|c|}{ Massa (g) } & \multirow{2}{*}{$\begin{array}{c}\text { Dầ metro } \\
\text { cm }\end{array}$} & \multirow{2}{*}{$\begin{array}{c}\text { Co mprimento } \\
\mathrm{cm}\end{array}$} \\
\hline & & & & Com & Não-Com & Total & MFC-Média & MFNC-Média & & \\
\hline \multirow[t]{2}{*}{ RubiaR } & Infectadas & $90,0 \mathrm{~A}$ & $1,8 \mathrm{~B}$ & $28 \mathrm{~B}$ & $476 \mathrm{~A}$ & $504 \mathrm{~A}$ & $202,7 \mathrm{~A}$ & $48,4 \mathrm{~A}$ & $7,1 \mathrm{~A}$ & $13,3 \mathrm{~A}$ \\
\hline & Sadias & $102,2 \mathrm{~A}$ & $1,0 \mathrm{D}$ & $61 \mathrm{~A}$ & $275 \mathrm{~A}$ & $336 \mathrm{~A}$ & $217,2 \mathrm{~A}$ & $69,3 \mathrm{~A}$ & $7,6 \mathrm{~A}$ & $12,8 \mathrm{~A}$ \\
\hline \multirow[t]{2}{*}{ Amanda } & Infectadas & $92,8 \mathrm{~A}$ & $1,45 \mathrm{C}$ & $70 \mathrm{~A}$ & $232 \mathrm{~A}$ & $302 \mathrm{~A}$ & $208,5 \mathrm{~A}$ & $76,3 \mathrm{~A}$ & $7,2 \mathrm{~A}$ & $14,2 \mathrm{~A}$ \\
\hline & Sadias & $85,0 \mathrm{~A}$ & $1,0 \mathrm{D}$ & $85 \mathrm{~A}$ & $208 \mathrm{~A}$ & $293 \mathrm{~A}$ & $185,3 \mathrm{~A}$ & $59,4 \mathrm{~A}$ & $7,0 \mathrm{~A}$ & $13,1 \mathrm{~A}$ \\
\hline \multirow[t]{2}{*}{ Magda } & Infectadas & $142,2 \mathrm{~A}$ & $2,3 \mathrm{~A}$ & $45 \mathrm{~A}$ & $626 \mathrm{~A}$ & $671 \mathrm{~A}$ & $67,0 \mathrm{~A}$ & $25,0 \mathrm{~A}$ & $4,9 \mathrm{~A}$ & $10,6 \mathrm{~A}$ \\
\hline & Sadias & $147,3 \mathrm{~A}$ & $1,0 \mathrm{D}$ & $69 \mathrm{~A}$ & $716 \mathrm{~A}$ & $785 \mathrm{~A}$ & $72,2 \mathrm{~A}$ & $24,3 \mathrm{~A}$ & $5,0 \mathrm{~A}$ & $10,6 \mathrm{~A}$ \\
\hline
\end{tabular}

Valores seguidos de mesma letra na coluna não diferem entre si pelo Teste de Tukey $(\mathrm{P}>0,05)$. Letras maiúsculas na coluna equivalem a comparação de média do mesmo cultivar. Legenda: Com: Comercial; Não-Com: Não Comercial; MFC-Média: Média da Massa de Fruto Comercial; MFNC-Média: Média da Massa de Fruto Não Comercial e cm: centímetro. Os valores obtidos para severidade dos sintomas, altura das plantas, tamanho (diâmetro e comprimento) e massa dos frutos comerciais e não comerciais, assim como a média da produção total de frutos produzidos por cultivar foram submetidos à análise de variância, sendo as médias contrastadas pelo Teste de Tukey a $5 \%$ de probabilidade. Os frutos classificados de acordo com as definições do CEAGESP (CEAGESP: meucarderno.com s/d) foram contabilizados e obtida a massa média dos frutos por cultivar. O parâmetro altura das plantas foi analisado separadamente para cada cultivar, devido às diferenças genéticas de cada um. O programa utilizado para analisar os dados foio Sistema para Análise e Separação de Médias em Experimentos Agrícolas (SASM-Agri), versão $3.2 .4(2)$ 
o período de adaptação e crescimento das plantas (após inoculação). A redução acentuada dos sintomas foi observada nos meses de junho e julho, que foram os mais frios do ano, com temperaturas em torno de $16,7^{\circ} \mathrm{C}$ e $18,3^{\circ} \mathrm{C}$, respectivamente. Paplomatas (5) já haviam observado que os sintomas de geminivírus variam de acordo com as condições ambientais e com a idade da planta hospedeira.

Com relação à produção de frutos comerciais e não comerciais, plantas infectadas pelo ToSRV mostraram redução na produção de frutos comerciais de $28 \%, 36,7 \%$ e $44,6 \%$ para as cultivares Rubia R, Magda e Amanda, respectivamente ( $1^{\circ}$ Experimento). Esta tendência foi observada no segundo experimento, porém não houve diferença estatística para as produções das cultivares Amanda e Magda. Para a cultivar Rubia R houve uma redução da ordem de $54 \%$ no número de frutos comerciais produzidos (Tabela 1).

Os parâmetros qualitativos dos frutos, como massa de frutos comerciais e não comerciais, diâmetro e comprimento dos frutos não foram significativamente afetados pela infecção com o vírus (Tabela 1). Esses resultados são semelhantes aos obtidos por Vecchia (8) e Giordano (3), em que não foi verificado efeito da infecção do tomateiro por begomovírus no peso médio dos frutos.

Em outros patossistemas também foi observado o efeito deletério da presença de begomovírus como no caso da redução de $37,6 \%$ na produção de frutos em plantas infectadas pelo ToYVSV (10) e redução de produtividade em torno de $60 \%$ em tomateiro infectado pelo Tomato chlorotic mottle virus (ToCMoV) (3).

A quantificação dos danos causados pode auxiliar na decisão de controle de uma doença. Em condições de campo o processo de infecção é gradual, com plantas infectadas no início do ciclo, no meio e no fim, causando dessa forma, danos variáveis. Pode-se concluir que o ToSRV, espécie prevalente em cultivos de pimentão no estado de São Paulo, casou nos três genótipos analisados redução no número de frutos comercias produzidos por planta, o que diretamente afeta o rendimento da cultura e traz perdas econômicas ao produtor.

\section{REFERÊNCIA BIBLIOGRÁFICA}

1. Althaus, R.A., Canteri, M.G., Giglioti, E.A. Tecnologia da informação aplicada ao agronegócio e ciências ambientais: sistema para análise e separação de médias pelos métodos de Duncan, Tukey e Scott-Knott. In: Encontro Anual de Iniciação Científica, Ponta Grossa. Anais. Ponta Grossa:Editora, 2001. Parte 1. p. $280-281$

2. Bezerra-Agasie, I.C.; Ferreira, G.B.; Ávila, A.C.; Inoue-Nagata, A.K. First report of Tomato severe rugose virus in chili pepper in Brazil. Plant Disease, Saint Paul, v.90, n.1, p.114, 2006.

3. Giordano, L.B.; Fonseca, M.E.N.; Silva, J.B.C.; Inoue-Nagata, A.K.; Boiteux, L.S. Efeito da infecção precoce por Begomovirus com genoma bipartido em características de frutos de tomate industrial. Horticultura Brasileira, Brasília DF, v.23, n.3 p.815-818, 2005.

4. Nozaki, D.N.; Krause-Sakate, R.; Pavan, M.A. Begomovírus infectando a cultura de pimentão no Estado de São Paulo. Summa Phytopathologica, Botucatu, v.36, n.3, p.244-247, 2010.

5. Paplomatas, E.J.; Patel, V.P.; Hou, Y.M.; Noueiry, A.O.; Gilbertson, R.L. Molecular characterization of a new sap-transmissible bipartite genome geminivirus infecting tomatoes in Mexico. Phytopathology, Saint Paul, v.84, p.1215-1224, 1994.

6. Rocha, K.C.G.; Marubayashi, J.M.; Navas-Castillo, J.; Pavan, M.A. Krause-Sakate, R. Ocorrência e variabilidade genética do Tomato severe rugose virus em tomateiro e pimentão no Estado de São Paulo. Summa Phytopathologica, Botucatu, v.36, n.3, p.222227, 2010 .

7. Stanley, J. Bisaro, D.M., Briddon, R.W., Brown, J.K., Fauquet, C.M., Harrison, B.D., Rybicki, E.P., Stenger, D.C. Geminiviridae. In Fauquet, C. M.; Mayo, M. A.; Mmaniloff, J., Dessselberger, U., Ball L.A. (eds), Virus Taxonomy. Eight Report of the International Committee on Taxonomy of Viruses. Elsevier/Academic Press, London, pp. 301-326, 2005.

8. Vecchia, M.G.S.D. Dinâmica temporal e espacial da begomovirose causada por Tomato yellow vein streak vírus em tomateiro na região de Campinas - SP. 2006. 91f. Tese (Doutorado em Agronomia) Escola Superior de Agricultura de Luiz de Queiroz, Universidade de São Paulo, Piracicaba. 